\title{
How realistically do the elementary school students approach to non-routine word problems?*
}

\author{
Çiğdem KILIÇ** Sinan OLKUN ${ }^{* * *}$ Hatice OLKUN ${ }^{* * * *}$
}

\begin{abstract}
The current study investigated middle grade (4 to 7th grade) students' solutions to non-standard word problems and changes in their solutions with respect to grade level, gender, and socio-economic status. A total of 915 students were participated in the study. Data were collected through a test with 5 open ended nonstandard word problems. Data were analyzed mainly through descriptive statistics. Group differences were analyzed via ratio test. Results showed that most of the students produced nonrealistic solutions to word problems. Many students either made technical mistakes or were not able to produce any solutions. The types of answers did not change with respect to gender but socio-economic status and grade level. Students in upper grades and with a relatively high socio-economic background more frequently gave realistic answers to problems.
\end{abstract}

Keywords: Word problems, student strategies, non-routine problems, realistic problems.

\footnotetext{
* A part of this study was presented in "IX National Mathematics and Science Education Conference" in 23-25 September 2010, in İzmir.

** Assist. Prof. Dr., Mersin University, Faculty of Education, Department of Mathematics Education, Mersin, Turkey. E-mail: ckilic6@gmail.com

${ }^{* * *}$ Prof.Dr. Ankara University, Faculty of Educational Sciences, Department of Primary Education, Ankara, Turkey. E-mail: sinanolkun@gmail.com

${ }_{* * * *}^{*}$ Classroom teacher, Vehbi Dinçerler Primary School,Ankara,Turkey. E-mail: hatticerdogan@gmail.com
} 


\section{SUMMARY}

Purpose and Significance: This study aimed at finding out middle grade (4 to 7th grade) students' solutions to non-standard word problems and whether the solutions that produced by participants vary according to their grade level, gender, and socio-economic levels. It is considered that solving realistic word problems contribute to the development of students' basic skills such as mathematical reasoning, connecting mathematical topics with daily life and developing new mathematical ideas.

Method: Data were collected through a problem solving test consisting of five non-standard word problems. The study was carried out with 915 students from 6 schools in 2 different provinces. The schools were selected from different sosyo-economic neighborhoods ranging from poor to high. Data were analyzed via the descriptive statistics and ratio test.

Results: Solutions of students were coded realistic, non-realistic, technical error, no answer and other. The findings of the research indicated that most of the students performed one or more operations and find a numerical answer but did not take into account the reality in solving nonstandard word problems. In solving problems some students made technical errors and some others were not able to give any answers. Among solutions of participants some solutions were coded as "other" which does not belong to any of the determined codes.

Discussion and Conclusions: Results showed that most of the students produced non-realistic solutions to problems. The findings of the study seem to be similar with the findings of the studies conducted in other countries (Verschaffel, De Corte \&Lasure, 1994; Yoshida, Verschaffel \& De Corte, 1997; Reusser \& Stebler, 1997; Xin et al, 2007; Palm, 2008). The types of solutions did not vary with respect to gender but socio economic background and grade levels. Students in upper grades and with high socio-economic status gave more frequently realistic answers to problems than do other students. Based on the results, it can be recommended that students should engage in solving these kinds of problems and teachers should provide learning environments which support students' non-standard word problem solving skills. The subtle reasons of unrealistic solutions of students can be investigated further in a qualitative study. 


\section{İlköğretim Öğrencileri Standart Olmayan Sözel Problemlerin Çözümlerine Ne Kadar Gerçekçi Yaklaşıyorlar?*}

\section{Çiğdem KILIÇ** Sinan OLKUN ${ }^{* * *}$ Hatice OLKUN ${ }^{* * * *}$}

ÖZ. Bu çalışma ile ilköğretim (4, 5, 6 ve 7 . sınıf) öğrencilerinin standart olmayan sözel problemlerin çözümlerine ne türden yanıtlar verdikleri ve verdikleri bu yanıtların sınıf, cinsiyet ve sosyo-ekonomik düzeylerine göre değişip değişmediğine bakılmıştır. Araştırmaya toplam 915 ilköğretim öğrencisi katılmıştır. Veriler 5 açık uçlu, sözel problemden oluşan problem çözme testi ile toplanmıştır. Verilerin analizinde yüzde ve frekans hesaplaması yoluna gidilmiştir. Daha sonra problemlere verilen yanitların sinif, cinsiyet ve sosyo-ekonomik düzey açısından farklılaşıp farklılaşmadığına ise oran testi ile bakılmıştır. Araştırmadan elde edilen bulgulara bakıldığında, öğrencilerin önemli bir kısmının standart olmayan sözel problemlere gerçekçi olmayan yanıtlar verdikleri, bunun yanı sıra problemlerin çözümü sırasında teknik hatalar yaptıkları, çok sayıda öğrencinin problemlere yanıt veremediği görülmüştür. Problemlere verilen yanıtların öğrencilerin içinde bulundukları sosyo-ekonomik düzeye ve sınıfa bağlı olduğu ancak cinsiyete bağlı olmadığı saptanmıştır. Üst sınıflar ve göreceli üst sosyo-ekonomik bölgede olan öğrenciler daha fazla sayıda gerçekçi yanıt vermişlerdir.

Anahtar Sözcükler: Sözel problemler, standart olmayan sözel problemler.

\footnotetext{
* Bu çalışmanın bir bölümü IX. Ulusal Fen Bilimleri ve Matematik Eğitimi Kongresinde sözlü bildiri olarak sunulmuştur.

** Yrd. Doç. Dr., Mersin Üniversitesi Eğitim Fakültesi Mersin, Türkiye. E-posta: ckilic6@gmail.com

${ }^{* * *}$ Prof.Dr.,Ankara Üniversitesi Eğitim Bilimleri Fakültesi Ankara, Türkiye.

E-posta: sinanolkun@gmail.com

**** Sınıf Öğretmeni, Vehbi Dinçerler İlköğretim Okulu Ankara, Türkiye. E-posta: hatticerdogan@gmail.com
} 


\section{GİRIŞ}

Sözel problemler ilköğretim matematik derslerinde sıklıkla kullanılmaktadır. Okul matematiğinde bu türden problemlere yer verilmesinin en önemli nedeni, öğrencilerin okulda öğrendikleri bilgi ve becerileri gerçek yaşama uygulamayı öğrenecekleri beklentisidir (Verschaffel, De Corte ve Lasure, 1994). Ayrica, sözel problemlerin öğrencilerin problem çözme kapasitelerini geliştirmede birer araç olduğu ve matematik derslerini daha zevkli hale getirme gibi işlevlerinin olduğu gerekçesiyle bu türden problemlerin öğretimde kullanıldığı belirtilmektedir (Verschaffel ve De Corte, 1997).Sözel problemler sayesinde öğrencilerde geliştiği iddia edilen bir takım bilgi ve beceriler şöyle özetlenebilir;

- Matematiksel süreçler arasında etkileşimler yapabilme (Reusser ve Stebler, 1997),

- Matematize etme, ya da matematikleştirme, yani matematiksel modelleme yapabilmede deneyim kazanma (Reusser ve Stebler, 1997),

- Matematiksel kavramların önemini anlama konusunda motive olma ve öğrencilerin yaratıcı, eleştirel ve problem çözme becerilerini geliştirme (Chapman, 2006),

- Okulda öğrenilen matematikle gerçek yaşam durumları arasında bağ kurabilme, ilişkilendirme(Greer, 1997; Chapman, 2006),

- Matematiksel akıl yürütme becerilerini geliştirme (Wyndhamn ve Saljö, 1997) ve

- Yeni matematiksel fikirler geliştirme (Souviney, 1994).

Sözel problemlerin standart olan ve olmayan biçiminde ikiye ayrıldığ görülmektedir (Olkun ve diğerleri, 2009; Verschaffel, De Corte ve Lasure, 1994;Reusser ve Stebler, 1997). Standart problemler, problemde verilen sayıları kullanarak dört işlemden bir ya da birden fazlasının seçilmesiyle kolayca çözülebilen problemler olarak ele alınırken, standart olmayan sözel problemler ise, matematiksel modellemenin zor olduğu ve problem durumunda yer alan gerçekleri göz önüne almayı gerektiren problemler olarak ifade edilmektedir.

Standart olmayan problemlerin standart olan problemler gibi hemen kolayca çözülemediği belirtilmektedir (Verschaffel, De Corte ve Lasure, 1994;Reusser ve Stebler, 1997; Xin ve diğerleri, 2007). Bunun nedeni de standart olmayan sözel problemlerin çözümüne "gerçek yaşam" bilgisinin de dâhil edilmesi gerekliliğidir (Xin ve diğerleri, 2007).Standart olan sözel probleme örnek olarak; "12 metre uzunluğundaki ip 1,5 metrelik parçalara ayrıldığı zaman kaç tane ip parçası elde edilir?” problem durumu verilebilir. 
$\mathrm{Bu}$ problem dört işlem uygulanarak kolayca çözülebilen bir problemdir. Standart olmayan sözel probleme örnek olarak "İki direğin arasındaki uzaklık 12 metredir. Bu iki direk arasına ip gerip çamaşır asmak isteyen birinin elinde uzunluğu 1,5 metre olan ip parçacıkları bulunmaktadır. Buna göre bu ip parçacıklarından kaç tane kullanmalıdır?" problem durumu verilebilir. Bu problemin çözümünde dört işlemden uygun olanları seçilerek bulunan sonucun, gerçek yaşamda olup olamayacağı konusunda fikir yürütülmesi de gerekmektedir. Standart olmayan sözel problemler "matematik" ile "gerçek" arasında bir köprü görevini görmektedir ve bu türden problemlerin çözümünde öğrencilerin bir takım bilişsel aşamalardan (durumları temsil etme, matematiksel modelleri kurma, çözümleri seçme ve sonuçları değerlendirme) geçmeleri gerektiği belirtilmektedir (Xin ve diğerleri, 2007).

Yapılan çalışmalar sınıf düzeyleri arttıkça öğrencilerin standart olmayan sözel problemlere daha çok gerçekçi yanıtlar verebildiklerini göstermektedir (Xin ve diğerleri, 2007; Öktem, 2009). Bu durum öğrencilerin kendi deneyimlerindeki artış ile açıklanmıştır. Yani öğrenciler deneyim kazandıkça gerçekçi problem çözme başarılarında artış olduğu ifade edilmiştir (Xin ve diğerleri, 2007). Öte yandan, sınıf düzeyi arttıkça öğrencilerin problem hakkında daha ayrıntılı düşünmelerinden ve gerçek yaşam bilgilerini problem çözmeye daha kolay uyarlayabilmelerinden kaynaklanıyor olabileceği de belirtmiştir (Öktem, 2009). Özetle, öğrencilerin sınıf düzeyleri arttıkça gerçekçi problem çözme becerilerinin de artması hem gelişimsel, hem de eğitimsel yani deneyimsel gerçeklere bağlı olabilir.

Matematik derslerinin çoğunda, öğrencilerin sözel problemleri genelde problemi "anla" ve "çöz" mantığı ile hareket ederek, gerçek yaşam uygulamaları ile matematiksel işlemler arasında bağ kurmadan (Reusser ve Stebler, 1997), problemde yer alan sayıları kullanarak, doğru hesaplamalar yaparak, ancak bulunan sonucun gerçek yaşamla olan ilişkisine bakmadan çözdükleri (Inoue, 2005) belirtilmektedir. Özellikle ilköğretim öğrencilerinin standart olmayan sözel problemleri çözerken problemde yer alan sayıları kullanarak bir takım hesaplamalar yapma eğiliminde oldukları, ancak hesaplamalar sonunda buldukları sonucun gerçeği yansitıp yansitmadığ durumunu göz önüne pek almadıkları ifade edilmektedir (Verschaffel, De Corte ve Lasure, 1994; Yoshida, Verschaffel ve De Corte, 1997; Reusser ve Stebler, 1997; Xin ve diğerleri, 2007; Palm, 2008;Öktem, 2009; Artut ve Aladağ, 2009).

Öğrencilerin standart olmayan sözel problemlere gerçekçi yanıtlar verememelerinin çeşitli nedenleri olduğu belirtilmektedir. $\mathrm{Bu}$ nedenler arasında sinıf kültürünün(Greer, 1997; Inoue, 2005;Gravemeijer, 1997; Hatano, 1997; Wyndhamn ve Saljö, 1997;Reusser ve Stebler, 1997; Verschaffel, De Corte ve Lasure, 1999; Xin ve diğerleri, 2007 ),öğrencilerin problem çözme becerilerinin (Inoue, 2005) ve okul matematiği ile ilgili 
alg1larının (Schoenfeld, 1991), problem durumlarını yorumlama biçimlerinin(Verschaffel, De Corte ve Lasure, 1999), problemlerin kalitesinin (Reusser ve Stebler, 1997) ve yapılarının (Verschaffel, De Corte ve Lasure, 1999;Gravemeijer, 1997), matematiğin gerçekle olan ilgisinin ve gerçeğin kendisinin göreceli (relative) bir kavram olmasının (Xin ve diğerleri, 2007) ve öğrenme ortamının (Palm, 2008) yer aldığı ifade edilmektedir.

$\mathrm{Bu}$ araştırmada aşağıdaki sorulara yanıt aranmıştır;

1. Öğrenciler standart olmayan problemlerin çözümlerine ne türden yanıtlar vermişlerdir?

2. Standart olmayan sözel problemlere verilen yanıtlar sinıf düzeylerine göre farklılaşmakta mıdır?

3. Standart olmayan sözel problemlere verilen yanitlar okulların bulunduğu sosyo-ekonomik çevreye göre farklılaşmakta mıdır?

4. Standart olmayan sözel problemlere verilen yanıtlarda cinsiyete göre farklılaşmakta mıdır?

\section{Araştırmanın Önemi}

Problem çözmenin bireyin hem okul, hem de günlük yaşantısında önemli bir yeri olduğu göz önüne alındığında, problem çözmenin etkili bir biçimde öğretilmesi kaçınılmazdır. Bu türden problemleri çözmenin etkili bir biçimde gerçekleşebilmesi için öncelikle öğrencilerin bu konularda ne durumda olduklarını belirlemek gerekmektedir. Standart olmayan sözel problemlerin çözümlerinde ilköğretim öğrencilerinin sıkıntılar yaşadığ 1 farklı ülkelerde yapılan araştırma bulgularıyla ortaya konulmuştur. Ancak Türkiye'de bu konuda yapılıış araştırma sayısı oldukça sınırlıdır. Özellikle öğrencilerin bu türden problemleri çözerken, gerçek yaşam bilgilerini de çözüme katıp katmadıkları ya da sınıf ve farklı sosyoekonomik düzeylerdeki öğrencilerin bunu ne düzeyde yaptıkları henüz araştırılmamıştır. $\mathrm{Bu}$ araştırma ile, ilköğretim öğrencilerinin standart olmayan sözel problemleri çözme biçimleri hakkında öğretmenlere ve araştırmacılara yararlı bilgiler sunulacağı düşünülmektedir.

\section{YÖNTEM}

\section{Çalışma Grubu}

$\mathrm{Bu}$ çalışma, Mersin ve Ankara'da yer alan 3ilköğretim okulundan ve farklı sınıf düzeylerinde (4, 5,6 ve 7. sınıflar)toplam 915 ilköğretim öğrencisi ile gerçekleştirilmiştir. Öğrencilerin dağılımı ise şöyledir;210 dördüncü sınıf, 300 beşinci sınıf,223 altıncı sınıf ve 182 yedinci sınıf. Araştırmanın yapıldığı 
okullar, her iki ilin de kendi ölçülerine göre düşük, orta ve yüksek sosyoekonomik düzey çevrelerde bulunan devlet okullarıdır.

\section{Verilerin Toplanması ve Analizi}

Araştırmada veri toplamak amacıyla araştırmacılar tarafindan 5 problemden oluşan açık uçlu bir problem çözme aracı geliştirilmiştir. Testte yer alan problemler uluslararası alan yazından (Inoue, 2005; Verschaffel, De Corte ve Lasure, 1994) derlenmiş, standart olmayan sözel problemlerdir. Hazırlanan problemler hakkında alan uzmanlarından görüşler alınıp daha sonra, problemler bir ilköğretim okulunda bulunan ilköğretim 4.,5., 6. ve 7. sınıf öğrencilerine (her bir sınıftan dörder öğrenci) pilot çalışma yapmak amacıyla yazılı olarak sunulmuş ve problemleri yanıtlamaları istenmiştir. Böylelikle problemlerin anlaşılır olup olmadığına bakılmıştır. Pilot çalışma sonunda bazı problemlerin ifadelerinde değişiklik yoluna gidilmiştir.

Problemlerin çözümü için bir ders saati süresi tanınmış olup, öğrencilerden problem çözme sırasında yazdıkları hiçbir şeyi silmemeleri istenmiştir. Böylece öğrencilerin problemleri çözüm yolları ya da çözememe nedenleri ortaya çıkarılmaya çalışılmıştır. Araştırmada kullanılan problemler Tablo 1'de verilmiştir.

Tablo 1.Araştırmada kullanılan standart olmayan sözel problemler

\begin{tabular}{cl}
\hline Problem & Standart olmayan sözel problemler \\
1 & $\begin{array}{l}\text { Bir koşucu } 100 \text { metreyi } 8 \text { saniyede koşmaktadır. Bu koşucu } 1000 \text { metreyi ne } \\
\text { kadar zamanda koşar? }\end{array}$ \\
2 & $\begin{array}{l}\text { Elinde } 843 \text { CD'si olan bir kişi bu CD’leri raflara dizmek istemektedir. Bir raf } \\
73 \text { CD aldığına göre, elindeki CD’leri kaç rafa yerleştirebilir? }\end{array}$ \\
3 & $\begin{array}{l}\text { Büşra ve Deniz aynı okula gitmektedirler. Büşra'nın evinin okula olan uzaklığı } \\
17 \text { km, Deniz'in evinin okula olan uzaklığı ise } 8 \text { km'dir. Buna göre Büşra'nın } \\
\text { evi ile Deniz'in evi arasındaki uzaklık ne kadardır? } \\
\text { Sinem'in 6, Cansu'nun 5 arkadaş1 vardır. Sinem ve Cansu birlikte bir parti } \\
\text { vermeye karar vermişlerdir. Partiye bütün arkadaşları geldiğine göre partide kaç } \\
\text { kişi vardır? } \\
\text { Yavuz 1999 yılında doğmuştur. Şuan 2010 yılında olduğumuza göre, Yavuz } \\
\text { kaç yaşındadır? }\end{array}$ \\
\hline
\end{tabular}

Öğrencilerin standart olmayan sözel problemlere verdikleri yazılı yanıtlar ve bu yanıtlara yönelik yazdıkları açıklamalardan elde edilen verilerin kodlanmasında Verschaffel, De Corte ve Lasure (1994) tarafindan geliştirilen sınıflamadan yararlanılmıştır. Bu sınıflama aşağıdaki gibidir:

Gerçekçi olmayan yanıt (GOY); problemde verilen sayılar kullanılarak dört işlemden birinin yada bir kaçının uygulanmasıyla problemi çözme durumu. 
Gerçekçi yanıt (GY);problemin çözümü sırasında dört işlemden uygun olanların kullanılması ile birlikte, problemde yer alan gerçek yaşam bilgisini de göz önünde bulundurarak problemi çözme durumu.

Teknik hata (TH);beklenen yanıtta olduğu gibi dört işlemden uygun olanları seçilerek çözülmeye çalışıldığı ancak işlem hatasının yapıldığ 1 durum.

Yanit verememe (YV);problemle ilgili herhangi bir işlem ya da açıklama yapılmadığı durum.

Diğer; beklenen yanıt, gerçekçi yanıt, teknik hata ya da yanıt verememe durumlarına uygun olmayan durum.

Öğrencilerin problemlere verdikleri yanıtların bulundukları sınıf, sosyoekonomik düzey ve cinsiyete göre değişip değişmediğini belirlemek için oran testi kullanılmıștır. Oran testi (p-oranı) iki yüzde arasındaki farkın, bu farkın standart hatasına bölünmesi ile elde edilir (Baykul,1996). İki yüzde arasındaki fark ve bu farkın standart hatasının bulunmasında Statistica10 istatistik paket programı kullanılmıştır.

\section{BULGULAR VE YORUM}

Öğrencilerin problemlere verdikleri yanıtlar gerçekçi yanıtlar, gerçekçi olmayan yanıtlar, teknik hata, yanıt verememe ve diğer olmak üzere 5 kategoride toplanmıştır. Verilen yanıtlar problem bazında aşağıdaki gibi kodlanmış ve gruplandırılmıştır. Her bir kategori içerisinde yer alan örnekler problem bazında tek tek verilmiştir. Öğrencilerin problemlere vermiş oldukları gerçekçi ve gerçekçi olmayan yanıt örnekleri problem bazında Tablo 2'de verilmiştir. 
Tablo 2.Gerçekçi ve gerçekçi olmayan yanıt örnekleri

\begin{tabular}{|c|c|c|}
\hline Problemler & Gerçekçi yanıtlar & Gerçekçi olmayan yanıtlar \\
\hline Problem 1 & $\begin{array}{l}\text { Gerçekçi yanıt verme durumu } \\
\text { yok }\end{array}$ & $\begin{array}{l}\text { - } 1000: 100=1010 \mathrm{x} 8=80 \\
80=1 \mathrm{dk} 20 \text { saniye. }\end{array}$ \\
\hline Problem 2 & $\begin{array}{l}\text { - } 843: 73=11 \text { kalan } 40 \text { kalan } \\
40 \text { taneyi de başka rafa } \\
\text { koymamiz lazım } 12 \text { raf }\end{array}$ & $\begin{array}{ll}\text { - } & 843: 73=1111 \text { tanesi rafa } \\
& \text { yerleşir. } 40 \text { tanesi de artar. } \\
\text { - } & 843: 73=11, . .\end{array}$ \\
\hline Problem 3 & $\begin{array}{l}\text { - } \quad \text { Bir sürü sonuç bulunabilir. } \\
\text { Çünkü evlerinin yeri } \\
\text { sonucu değiştirir. } \\
\text { - } \quad \text { Bu sorunun cevabı kesin } \\
\text { olarak bilinemez } 9 \text { ile } 25 \\
\text { arası. } \\
\text { - Okula göre evlerinin } \\
\text { doğrultularına bağlı. } \\
\text { - Büşra ve Deniz'in evinin } \\
\text { aynı yönde olup olmadığını } \\
\text { bilmiyoruz. }\end{array}$ & $\begin{array}{ll}\text { - } & 17+8=25 \mathrm{~km} \\
\text { - } & 17-8=9 \mathrm{~km}\end{array}$ \\
\hline Problem 4 & $\begin{array}{l}\text { - Ama ortak arkadaşlarının } \\
\text { olup olmadığını bilmiyoruz } \\
\text { - Arkadaşları aynı kişilerde } \\
\text { olabilir. }\end{array}$ & - $\quad 6+5=11$ kişi \\
\hline Problem 5 & $\begin{array}{l}\text { - } 2010-1999=11 \text { ancak } 11 \text { ya } \\
\text { da 10,5 olabilir. Çünkü } \\
\text { insanlar yılbaşında yaş } \\
\text { atmazlar. Yani doğum } \\
\text { günlerine bağlıdır. } \\
\text { - } 2010-1999=11 \text { burada } 11 \\
\text { çıar ama eğer doğum } \\
\text { günü gelmişse } 11 \\
\text { gelmemişse daha } 10 \\
\text { yaşındadır. } \\
\text { Yavuz'un tam yaşını } \\
\text { bilmemiz için gün ve ay } \\
\text { tarihini de vermesi gerekir. } \\
\text { Bu yüzden } 10 \text { yaşında da } \\
\text { olabilir. }\end{array}$ & - $2010-1999=11$ yaşındadır. \\
\hline
\end{tabular}


Öğrencilerin standart olmayan sözel problemlerin çözümü sırasında yapmış oldukları teknik hatalar, yanıt verememe durumları ve diğer yanıtları problem bazında ele alınmış olup, bu durum Tablo 3'te verilmiştir.

Tablo 3.Teknik hata, yanıt verememe ve diğer yanıtını verme örnekleri

\begin{tabular}{|c|c|c|c|}
\hline Problemler & Teknik hata & Yanit verememe & Diğer \\
\hline Problem 1 & $1000: 100=10100 \times 8=800$ & $\begin{array}{l}\text { Bir koşucu } 100 \text { metreyi } 8 \\
\text { saniyede koşmaktadır. } \\
\text { Bu koşucu } 1000 \text { metreyi } \\
\text { ne kadar zamanda koşar? }\end{array}$ & $\begin{array}{l}2800 \mathrm{~km} \\
\text { koşar. }\end{array}$ \\
\hline Problem 2 & $\begin{array}{l}843: 73=11,5 \\
843: 73=121\end{array}$ & Anlamadım??? & $843-73=830$ \\
\hline Problem 3 & ${ }_{17-8}^{8}=11 \quad 17 \quad 11 \mathrm{~km}$ & & $4,5 \mathrm{~km}$ \\
\hline Problem 4 & --------- & ----------- & $6 \times 5=30$ \\
\hline Problem 5 & $\begin{array}{l}2010-1999=3109 \\
2010-1999=9 \\
2010-1999=12\end{array}$ & Bilmiyorum. & $1999+2010=11009$ \\
\hline
\end{tabular}

Öğrencilerin standart olmayan sözel problemlere verdikleri yanıtlar, sınıf düzeyleri de dikkate alınarak yapılan frekans ve yüzde hesaplamaları ile Tablo 4'te verilmiştir.

Tablo 4.Öğrencilerin standart olmayan sözel problemlerin çözümlerine yönelik olarak verdikleri yanitlar ve bu yanitların sinıf düzeyine göre frekans ve yüzde dağllimları

\begin{tabular}{|c|c|c|c|c|c|c|c|c|}
\hline \multirow[b]{3}{*}{ Yanitlar } & \multicolumn{8}{|c|}{ SINIFLAR } \\
\hline & \multicolumn{2}{|c|}{$\begin{array}{r}\text { 4. sinif } \\
\mathrm{N}=210\end{array}$} & \multicolumn{2}{|c|}{$\begin{array}{l}\text { 5. Sinif } \\
\mathrm{N}=300\end{array}$} & \multicolumn{2}{|c|}{$\begin{array}{l}\text { 6. sinif } \\
\mathrm{N}=223\end{array}$} & \multicolumn{2}{|c|}{$\begin{array}{l}\text { 7. sinif } \\
\mathrm{N}=182\end{array}$} \\
\hline & $\mathrm{f}$ & $\%$ & $\mathrm{f}$ & $\%$ & $\mathrm{f}$ & $\%$ & $\mathrm{f}$ & $\%$ \\
\hline GY & 69 & 7 & 147 & 10 & 112 & 10 & 129 & 14 \\
\hline GOY & 674 & 64 & 1114 & 74 & 757 & 68 & 602 & 66 \\
\hline $\mathrm{TH}$ & 77 & 7 & 48 & 3 & 44 & 4 & 55 & 6 \\
\hline YV & 70 & 7 & 84 & 6 & 86 & 8 & 54 & 6 \\
\hline Diğer & 160 & 15 & 107 & 7 & 126 & 10 & 70 & 8 \\
\hline
\end{tabular}

Tablo 4'te görüldüğü gibi, bütün sinıf düzeylerinde ilköğretim öğrencilerinin büyük çoğunluğu standart olmayan sözel problemlerin çözümlerine gerçekçi olmayan yanıtlar vermişlerdir. Az sayıda öğrencinin gerçekçi yanıtlar verdikleri, bunun yanı sıra kimi öğrencilerin problemlerin çözümü sırasında teknik hata yaptıkları ya da problemlere yanıt veremedikleri görülmüştür. Yine bir kısım öğrencinin problemlere gerçekçi 
yanıt, gerçekçi olmayan yanıt, teknik hata ve yanıt verememe durumlarına uymayan "diğer" yanıtını verdikleri belirlenmiştir.

Tablo 4'e bakıldığında, problemlere gerçekçi olmayan yanıt verme yüzdesinin diğer yanıtlara göre daha yüksek olduğu tüm sınıf düzeylerinde gözlenmiştir. Gerçekçi olmayan yanıt verme durumu en az 4. sınıf, en yüksek ise 5. sınıf öğrencilerinde görülmüştür. Gerçekçi yanıt verme yüzdesinin ise sınıf düzeyi arttıkça doğru orantılı olarak arttığı görülmüştür. Gerçekçi yanıt verme durumunun sınıf düzeyi ile doğru orantılı olarak arttığı, gerçekçi olmayan yanıt vermede ise 4.sınıftan 5.sınıfa doğru bir artma olduğu, ancak bu durumun 6. sinıftan 7. sinıfa doğru bir azalmaya dönüştüğü belirlenmiştir. Teknik hatanın ise 4 . sınıfta en yüksek, 5 . sınıfta da en az olduğu, 5. sınıftan 7. sınıfa doğru teknik hata yüzdesinde doğru orantılı bir artış olduğu görülmektedir. Problemlere yanıt verememe durumu ise en fazla 6. sinıfta, en az ise 5. ve 7. sinıfta olduğu görülmüştür. Diğer yanıtının ise en yüksek 4. sınıfta en az da 5. sinıfta verildiği tespit edilmiştir. Problemlere verilen yanıtların sınıf düzeyine göre farklılık gösterip göstermediği ise sınıflar arasında ikişerli karşılaştırmalar yapılarak belirlenmiştir.

Problemlere gerçekçi yanıt verme sıklığında sınıflar arasında bir farklılaşma olup olmadığına bakıldığında sadece 4. sınıf öğrencilerin gerçekçi yanıt verme oranları ile 7. sınıf öğrencilerinin gerçekçi yanıt verme oranları arasında istatistiksel olarak anlamlı fark $(\mathrm{p}=.02, \mathrm{p}<05)$ bulunmuştur. Diğer ikili karşılaştırmalarda istatistiksel olarak anlamlı bir fark bulunamamıştır. Problemlere gerçekçi yanıtlar verme 4. sınıfta en az iken 7. sınıfta bu oran iki katına çıkmış ancak toplamda hala \%14 düzeyinde kalmıştır.

Problemlere gerçekçi olmayan yanıt verme sıklığında sınıflar arasında bir farklılaşma olup olmadığına bakıldığında; 4. sınıf ile 5. sınıf arasındaki farkın $(\mathrm{p}=.01, \mathrm{p}<.05)$ istatistiksel olarak anlamlı olduğu, diğer sınıflar arasında istatistiksel olarak bir fark bulunmadığı görülmüş̧ür. 5. sınıfların 4. sınıflara oranla gerçekçi olmayan yanıt verme oranı daha yüksektir.

Problemlerin çözümü sırasında teknik hata yapma sıklığında sınıflar arasında bir farklılaşma olup olmadığına bakıldığında; 4. sınıf ile 5. sınıf arasinda $(p=.03, p<.05), 4$. sinif ile 7. sinif arasinda $(p=.68$, $\mathrm{p}>$.05)istatistiksel olarak anlamlı farklar bulunmuş, diğer sınıflar arasında istatistiksel olarak bir fark bulunamamıştır. Dördüncü sınıfların 5. ve 7 . sınıflara oranla problemlerin çözümü sırasında teknik hata yapma oranı daha yüksek bulunmuştur.

Problemlerin çözümü sırasında yanıt verememe sıklığında sınıflar arasında istatistiksel olarak bir fark bulunmamıştır. Problemlere yanıt verememe oranı tüm sınıf düzeylerinde hemen hemen aynıdır. Ayrıca, 
problemlere yanıt verememe yüzdesinin (\%6-8) matematik öğrenme güçlügünün yaygınlığı ile ilgili yapılan araştırmalarda(Shalev, Auerbach, Manor, ve Gross-Tsur, 2000) bulunan matematik öğrenme güçlüğü çeken öğrencilerin yüzdesine (\%5-8)benzerliği dikkat çekicidir.

Problemlerin çözümü sırasında diğer yanıtını verme sıklığında sınıflar arasında bir farklılaşma olup olmadığına bakıldığında; 4. sınıf ile 5. sınıf arasindaki $(\mathrm{p}=.003, \mathrm{p}<.05)$ ve 4 . sinif ile 7 . sinif arasindaki $(\mathrm{p}=.03, \mathrm{p}<.05)$ farkların istatistiksel olarak anlamlı olduğu, diğer sınıflar arasındaki farkların ise istatistiksel olarak anlamlı olmadığı bulunmuştur. Problemlerin çözümü sırasında teknik hata yapma oranı en çok 4. sınıflarda görülmüştür. Standart olmayan sözel problemlere öğrencilerin vermiş oldukları yanıtların sosyoekonomik düzeyler dikkate alınarak yapılan frekans ve yüzde hesaplamaları Tablo 5'te verilmiştir.

Tablo 5.Öğrencilerin standart olmayan sözel problemlerin çözümlerine yönelik olarak verdiklerin yanıtların sosyo-ekonomik düzeylerine göre frekans ve yüzde dağıllmlarl

\begin{tabular}{llclclc}
\hline & \multicolumn{5}{c}{ Sosyo-ekonomik düzeyler } \\
\cline { 2 - 7 } Yantlar & \multicolumn{5}{c}{$\begin{array}{c}\text { Düşük } \\
\mathrm{N}=303\end{array}$} & \multicolumn{4}{c}{$\begin{array}{c}\text { Orta } \\
\mathrm{N}=168\end{array}$} & $\begin{array}{c}\text { Yüksek } \\
\mathrm{N}=444\end{array}$ \\
\cline { 2 - 7 } & $\mathrm{f}$ & $\%$ & $\mathrm{f}$ & $\%$ & $\mathrm{f}$ & $\%$ \\
GY & 39 & 3 & 53 & 6 & 352 & 16 \\
GOY & 926 & 61 & 610 & 73 & 1614 & 73 \\
TH & 116 & 8 & 44 & 5 & 64 & 3 \\
YV & 139 & 9 & 51 & 6 & 104 & 4 \\
Diğer & 295 & 19 & 82 & 10 & 86 & 4 \\
\hline
\end{tabular}

Tablo 5'e bakıldığında problemlere gerçekçi yanıt verme yüzdesinin sosyo-ekonomik düzeyleri düşük olan öğrencilerde en az, orta olan öğrencilerde biraz daha fazla yüksek olan öğrencilerde ise en çok olduğu görülmüştür. Gerçekçi olmayan yanıt verme yüzdesinin sosyo-ekonomik düzeyleri düşük olan öğrencilerde en az, orta ve yüksek olan öğrencilerde ise daha çok olduğu tespit edilmiştir. Teknik hata, yanıt verememe ve diğer yanıtını verme yüzdelerinin sosyo-ekonomik düzeyleri düşük olan öğrencilerde en çok, yüksek olan öğrencilerde ise en az olduğu görülmüştür. Problemlere gerçekçi yanıtlar ve gerçekçi olmayan yanıtlar verme sıklığının sosyo- ekonomik düzeyi artıkça doğru orantılı bir biçimde arttı̆̆1, teknik hata, yanıt verememe ve diğer yanıtların ise azaldığı görülmektedir.

Problemlere gerçekçi, gerçekçi olmayan yanıt, teknik hata, yanıt verememe ve diğer yanıtlarını vermeleri açısından gruplar arasında anlamlı bir fark olup olmadığına ikişerli karşılaştırmalar yapılarak bakılmıştır. Problemlere gerçekçi yanıt verme sıklığına bakıldığında, sosyo- ekonomik 
düzeyi düşük ve orta olanlar arasındaki ( $p=.11, p>.05)$, sosyo-ekonomik düzeyi orta ve yüksek olanlar arasındaki $(\mathrm{p}=.001, \mathrm{p}<.05)$, sosyo-ekonomik düzeyi düşük ve yüksek olanlar arasındaki $(\mathrm{p}=.00, \mathrm{p}<.05)$ oranlar farklı bulunmuştur. Sosyo- ekonomik düzeyi düşük ve orta olanlar arasında istatistiksel olarak anlamlı fark olmazken, sosyo-ekonomik düzeyleri yüksek olan öğrenciler ile orta olan öğrenciler arasında ve yüksek olanlar ile düşük olanlar arasında istatistiksel olarak fark olduğu görülmüştür. Sosyoekonomik düzeyi yüksek olan öğrencileri problemlere gerçekçi yanıt verme oranları yüksek ve orta sosyo-ekonomik düzeydeki öğrencilerden daha yüksektir.

Problemlere gerçekçi olmayan yanıtlar verme sıklığında sosyoekonomik düzeylerine göre farklılaşma olup olmadığına bakıldığında; sosyoekonomik düzeyi düşük ve orta olanlar arasında $(\mathrm{p}=.0088, \mathrm{p}<.05)$, sosyoekonomik düzeyi orta ve yüksek olanlar arasında $(\mathrm{p}=1, \mathrm{p}>.05)$, sosyoekonomik düzeyi düşük ve yüksek olanlar arasında $(\mathrm{p}=.005, \mathrm{p}<.05)$ oranlar farklı bulunmuştur. Sosyo- ekonomik düzeyi düşük olanlar ile orta olanlar arasında ve düşük olanlar ile yüksek olanlar arasında istatistiksel olarak anlamlı fark varken, orta ile yüksek olanlar arasında fark olmadığ görülmüştür. Problemlere gerçekçi olmayan yanıtlar verme sıklı̆̆ en az sosyo-ekonomik düzeyi düşük olan öğrencilerde görülmüştür.

Problemlerin çözümü sırasında teknik hata yapma sıklığında sosyoekonomik düzeylerine göre farklılaşma olup olmadığına bakıldığında; sosyoekonomik düzeyi düşük ve orta olanlar arasında $(\mathrm{p}=.22, \mathrm{p}>.05)$, sosyoekonomik düzeyi orta ve yüksek olanlar arasında $(\mathrm{p}=.23 \mathrm{p}>.05)$, sosyoekonomik düzeyi düşük ve yüksek olanlar arasında ( $\mathrm{p}=.0021, \mathrm{p}<.05)$ anlamlı farklar bulunmuştur. Sosyo- ekonomik düzeyi düşük ve orta olanlar arasında ve orta ile yüksek olanlar arasında istatistiksel olarak anlamlı fark olmazken, düşük olanlar ile yüksek olanlar arasında fark olduğu görülmüştür. Problemlerin çözümü sırasında teknik hata sıklığının en az sosyo-ekonomik düzeyi yüksek, en çok da sosyo-ekonomik düzeyi düşük olan öğrencilerde görülmüştür.

Problemlerin çözümü sırasında yanıt verememe sıklığında sosyoekonomik düzeylerine göre farklılaşma olup olmadığına bakıldığında; sosyoekonomik düzeyi düşük ve orta olanlar arasında $(\mathrm{p}=.25, \mathrm{p}>.05)$, sosyoekonomik düzeyi orta ve yüksek olanlar arasında $(\mathrm{p}=.29, \mathrm{p}>.05)$, sosyoekonomik düzeyi düşük ve yüksek olanlar arasında $(\mathrm{p}=.0048, \mathrm{p}<.05)$ oranlar arasında fark bulunmuştur. Sosyo- ekonomik düzeyi düşük ve orta olanlar arasında ve orta ile yüksek olanlar arasında istatistiksel olarak fark olmazken, düşük olanlar ile yüksek olanlar arasında istatistiksel olarak fark olduğu görülmüştür. Problemlerin çözümü sırasında yanıt verememe 
sıklığının en az sosyo-ekonomik düzeyi yüksek, en çok da sosyo-ekonomik düzeyi düşük olan öğrencilerde görülmüştür.

Problemlerin çözümü sırasında diğer yanıtını verme sıklığının sosyoekonomik düzeyi artıkça azaldığı görülmektedir. Sosyo- ekonomik düzeyi düşük ve orta olanlar arasında $(\mathrm{p}=.0103, \mathrm{p}<.05)$, sosyo-ekonomik düzeyi orta ve yüksek olanlar arasında $(\mathrm{p}=.0041, \mathrm{p}<.05)$, sosyo-ekonomik düzeyi düşük ve yüksek olanlar arasında $(\mathrm{p}=.000, \mathrm{p}<.05)$ oranlar arasında fark bulunmuştur. Sosyo- ekonomik düzeyi düşük ve orta olanlar arasında ve orta ile yüksek olanlar arasında, düşük olanlar ile yüksek olanlar arasında fark olduğu görülmüştür. Gruplar arasında istatistiksel olarak anlamlı fark olduğu saptanmıştır. Problemlerin çözümü sırasında diğer yanıtını verme sıklığının en az sosyo-ekonomik düzeyi yüksek, en çok da sosyo-ekonomik düzeyi düşük olan öğrencilerde görülmüsstür.

Tablo 6. Ögrencilerin standart olmayan sözel problemlerin çözümlerine yönelik olarak verdiklerin yanttların cinsiyet durumları göre frekans ve yüzde dağgllmları

\begin{tabular}{lcccc}
\hline & \multicolumn{5}{c}{ CINSIYET } \\
\cline { 2 - 5 } \multicolumn{1}{c}{ YANITLAR } & & K1Z & & Erkek \\
& & $\mathrm{N}=459$ & & $\mathrm{~N}=456$ \\
& & & & \\
\cline { 2 - 6 } & & $\%$ & $\mathrm{f}$ & $\%$ \\
GY & $\mathrm{f}$ & 10 & 220 & 10 \\
GOY & 228 & 69 & 1559 & 68 \\
TH & 1587 & 5 & 118 & 5 \\
YV & 106 & 7 & 134 & 6 \\
Diğger & 160 & 9 & 249 & 11 \\
\hline
\end{tabular}

Standart olmayan sözel problemlere kız ve erkek öğrencilerin vermiş oldukları yanıtların frekans ve yüzde dağılımları Tablo 6'da verilmiştir. Tablo 6'ya bakıldığında, kız ve erkek öğrencilerin problemlere gerçekçi, gerçekçi olmayan yanıt verme ve problemlerin çözümü sırasında teknik hata yapma, yanıt verememe ve diğer yanıtlar verme sıklığının da birbirine çok yakın olduğu görülmüştür. Kız ve erkek öğrencilerin problemlere verdikleri yanıt türleri oranları arasında istatistiksel olarak anlamlı bir fark bulunmamıştır.

\section{SONUÇ VE ÖNERILER}

İlköğretim $(4,5,6$ ve 7. sinıf) öğrencilerinin standart olmayan sözel problemlere verdikleri yanıtlar incelendiğinde öğrencilerin standart olmayan sözel problemlere gerçekçi ve gerçekçi olmayan yanıtları vermelerinin yanı 
sıra, problemlerin çözümü sırasında teknik hata yaptıkları ya da problemlere yanıt veremedikleri gözlenmiştir. Bunların dışında diğer yanıtı kapsamına giren yanıtlar verdikleri de saptanmıştır. Öğrencilerin problemlere verdikleri yanıtlara bakıldığında beklendiği gibi büyük oranda gerçekçi olmayan yanıtlar verdikleri görülmektedir. Farklı ülkelerde bu konu ile ilgili olarak ilköğretim öğrencileri ile yapılan çalışmalarda da benzer bulgular elde edilmiştir (Verschaffel, De Corte ve Lasure, 1994;Yoshida, Verschaffel ve De Corte, 1997;Reusser ve Stebler, 1997;Xin ve diğerleri, 2007;Palm, 2008). Öğrencilerin standart olmayan sözel problemleri çözerken, problemleri standart problemler gibi çözdükleri, dört işlemden birini ya da birkaçını seçerek işlem yaptıkları, ancak buldukları bu sayısal sonucun gerçekle olan ilgisini ise pek dikkate almadıkları belirlenmiştir (Yoshida, Verschaffel ve De Corte 1997; Palm, 2008;Öktem, 2009). Bu durum öğrencilerin bu problem türü ile daha önceden karşılaşmamış olmaları ya da onların problem çözme ile ilgili mevcut algıları ile açıklanabilir.

Problemlere gerçekçi olmayan yanıt vermede 4. sınıf ile 5. sınıf arasında bir farklılaşma olmuştur. Ancak, diğer sınıf düzeyleri arasında ise bir farklılaşma olmamıştır. 5. sınıfta problemlere gerçekçi olmayan yanıt verme oranı diğer sinıflara göre daha çoktur. Genel olarak problemlere gerçekçi olmayan yanıt vermenin her sınıf düzeyinde aynı oranda ortaya çıktığı söylenebilir. Probleme doğru yanıt verme ya gerçekçi ya da gerçekçi olmayan yanıt şeklinde olmaktadır. Bu nedenle öğrencilerin öncelikle problemi doğru yanıtlamak kaygısıyla gerçekçi olmayan yanıtlara yöneldikleri daha sonra sınıfları ilerledikçe gerçekçi yanıtları da keşfettikleri düşünülebilir.

Öğrencilere toplu olarak bakıldığında, standart olmayan sözel problemlerin çözümlerine gerçekçi yanıtlar verildiği de görülmüştür. Ancak bu oran beklenen gerçekçi yanıt yüzdesinden daha azdır (Verschaffel, De Corte ve Borghart, 1997; Reusser ve Stebler, 1997; Verschaffel, De Corte ve Lausure, 1994; Yoshida, Verschaffel ve De Corte, 1997). Öğrenciler problemde yer alan sayıları kullanarak dört işlemden bir ya da bir kaçını kullanarak problemleri çözmüşlerdir. Daha sonra buldukları bu sonucun gerçek yaşamla olan ilgisine bakmışlardır. Öğrencilerin problemlere verdikleri yanıtlar sınıf düzeylerine göre incelendiğinde, gerçekçi yanıt verme oranlarının sınıf düzeyleri ile birlikte arttığ görülmektedir. Ancak sadece 4. sınıf ile 7. sınıf arasında anlamlı bir farklılaşma oluşmaktır. Farklı ülkelerde yapılan araştırmalarda da sınıf düzeyi ilerledikçe öğrencilerin problemlere gerçekçi yanıtlar vermelerinde bir artış olduğu belirlenmiştir (Xin ve diğerleri, 2007;Öktem, 2009).Standart olmayan sözel problemlere gerçekçi yanıt vermede sınıf düzeyi ile doğru orantılı bir sonucun çıkması 
durumu, öğrencilerin problem çözme ile ilgili sahip oldukları deneyimlerin artması ve algıların gelişmesi ile açıklanabilir.

Farklı ülkelerde yapılan araştırmalara (Verschaffel, De Corte ve Borghart, 1997;Reusser ve Stebler, 1997; Verschaffel, De Corte ve Lausure, 1994; Yoshida, Verschaffel ve De Corte, 1997) paralel olarak teknik hata, yanıt verememe durumlarının ise pek fazla yaşanmadığı, ancak herhangi bir yanıt türüne girmeyip "diğer" grubunda yer alan yanıtlar verildiği de saptanmıştır. Teknik hata, yanıt verememe ve diğer yanıtını verme durumlarının ise sınıf düzeylerine göre farklılaşıp farklılaşmadığına bakıldığında, teknik hata ve yanıt verememede siniflar arasında bir farklılaşma olmazken, diğer yanıtını vermede farklılaşmalar olmuştur. Problemlere gerçekçi, gerçekçi olmayan ve diğer yanıtını vermede sınıflar arasında bir farklılaşma olduğu, teknik hata ve yanıt verememede ise bir farklılaşma olmadığı görülmektedir. Bu türden problemlerin çözümlerinde ilköğretim öğrencilerinin genelde sorunlarının ortak olduğu söylenebilir.

Standart olmayan sözel problemlere verilen yanitlarda okulların bulunduğu sosyo-ekonomik çevreye göre bir farklilaşma olduğu belirlenmiştir. Sosyo-ekonomik düzeyi yüksek olan öğrenciler düşük ve orta olan öğrencilere göre problemlere daha gerçekçi çözümler üretmişlerdir. Problemlere gerçekçi olmayan yanıtları ise en çok sosyo- ekonomik düzeyi orta ve yüksek olan öğrencilerin, en az da düşük sosyo-ekonomik düzey olan öğrencilerin verdiği belirlenmiştir. Problemlerin çözümü sırasında teknik hata yapma, yanıt verememe ve diğer yanıtını verme durumlarının ise en çok düşük sosyo-ekonomik düzeye sahip öğrencilerde, en az da yüksek sosyoekonomik düzeye sahip öğrencilerde görülmüştür. Sosyo-ekonomik düzeyleri gelişmiş olan ailelerin çocukların matematikte daha başarılı olmaları (Dursun ve Dede, 2004) ile paralellik gösteren bu bulguya göre, sosyo-ekonomik düzeyin öğrencilerin gerçekçi yanıt gerektiren problemlerin çözümlerinde de etkili olduğu söylenebilir.

Problemlere verilen yanıt türleri ile cinsiyet arasında bir farklılaşma olup olmadığına bakıldığında, problemlere verilen yanıt türleri oranlarının birbirine yakın olduğu gözlenmiştir. Problemlere gerçekçi, gerçekçi olmayan yanıt verme, teknik hata ve yanıt verememe ve diğer yanıtını verme oranları arasında cinsiyet açısından istatistiksel olarak anlamlı bir fark olmadığ 1 görülmüştür. İlköğretim (4,5, 6 ve 7. sınıf) öğrencilerinin standart olmayan sözel problemleri çözmelerinde cinsiyet değişkenin etkili olmadığı ancak bulundukları sosyo-ekonomik düzeyin ve sınıfın (Xin ve diğerleri, 2007; Öktem, 2009) etkili olduğu belirlenmiştir.

Elde edilen sonuçlara bakıldığında, problemlere gerçekçi yanıt verme oranının genel olarak düşük olduğu söylenebilir. Bunun da öğrencilerin bu türden problemlerle karşılaşmamış olmaları ihtimalinin yüksek olmasından, 
ya da sınıf ortamında ağırlıklı olarak standart olan sözel problemlere ve bunların çözümlerine yer verilmesinden, ayrıca problem çözme sırasında gerçek yaşam bilgisi ile problemin çözümünün pek ilişkilendirilmediğinden kaynaklanabileceği söylenebilir. Oysa matematiğin yaşam içerisindeki öneminin fakına varma ve yaşamı matematik içerisinde tecrübe etme matematik eğitiminin amaçlarından biri olmalıdır. Standart olmayan problemleri çözen bireyler hem matematiğin günlük yaşam uygulamaları ile olan bağlantısını takdir edecek, hem de problem çözmenin yalnızca bir sonuç bulma olmadığını anlayarak problem çözme ile ilgili algıları da değişecektir.

Araştırmadan elde edilen sonuçlara bağlı olarak şu öneriler geliştirilebilir: Öğrenciler standart olmayan sözel problemlerle daha çok meşgul olmalıdırlar ve bu türden problemlerin çözümlerine ilköğretimin ilk yıllarından itibaren yer verilerek öğrencilerin problem çözme ile ilgili algıları geliştirilmelidir. Öğretmenler bu türden problemlerin çözümü için gerekli öğrenme ortamını hazırlamalıdırlar. Öğrencilerin problemlere gerçekçi çözümler üretememelerinin altında yatan temel nedenler araştırılabilir. Farklı öğretim yöntemlerinin öğrencilerin bu türden problemleri çözmelerine yönelik katkılarına bakılabilir.

\section{KAYNAKLAR}

Artut, P. D. ve Aladağ, A. (1-3 Ekim 2009). İlköğretim öğrencilerinin orantısal akıl yürütmeye dayal sözel problemler ile gerçekçi cevap gerektiren problemleri çözme becerilerinin incelenmesi. XVIII. Ulusal Eğitim Bilimleri Kurultayında sunulmuş bildiri. İzmir.

Baykul, Y. (1996). İstatistik: Metotlar ve Uygulamalar. Ankara: Anı Yayıncılık.

Chapman, O. (2006). Classroom practices for context of mathematics Word problems. Educational Studies in Mathematics, 62, 211-230.

Dursun, Ş. ve Dede, Y. (2004). Öğrencilerin matematikte başarısını etkileyen faktörler: Matematik öğretmenlerinin görüşleri bakımından. Gazi Üniversitesi Gazi Eğitim Fakültesi Dergisi, (24)2, 217-230.

Gravemeijer, K. (1997). Commentary solving word problems: A case of modeling. Learning and Instruction, 7(4), 389-397.

Greer, B. (1997). Modelling reality in mathematics classrooms: The case of Word problems. Learning and Instruction, 7 (4), 293-307.

Hatano, G. (1997). Commentary cost and benefit of modeling activity. Learning and Instruction, 7(4), 383-387.

Inoue, N. (2005).The realistic reasons behind unrealistic solutions: The role of interpretive activity in word problem solving. Learning and Instruction, 15, 6983. 
Olkun, S., Şahin, Ö., Akkurt, Z., Dikkartın, F.T. ve Gülbağcı, H. (2009). Modelleme yoluyla problem çözme ve genelleme: İlköğretim öğrencileriyle bir çalışma. Eğitim ve Bilim, 34(151), 65-73.

Öktem, S.P. (2009). İlköğretim ikinci kademe öğrencilerinin gerçekçi cevap gerektiren matematiksel sözel problemleri çözme becerileri. Yüksek Lisans Tezi.Çukurova Üniversitesi Sosyal Bilimler Enstitüsü.

Palm, T. (2008). Impact of authenticity on sense making in word problem solving. Educational Studies in Mathematics, 67,37-58.

Reusser, K.,\& Stebler, R. (1997).Every word problem has a solution - The social rationality of mathematical modeling in schools. Learning and Instruction, 7, 309-327.

Shalev, R. S., Auerbach, J., Manor, O.,\&Gross-Tsur, V. (2000). Developmental dyscalculia prevalence and prognosis. European Child \& Adolescent Psychiatry, 9(2), 58-64.

Souviney, R. J. (1994). Learning to teach mathematics $\left(2{ }^{\text {nd }}\right.$ Ed.). Englewood Cliffs: Macmillan Publishing Company.

Verschaffel, L., De Corte E.\& Lasure, S. (1994). Realistic considerations in mathematical modeling of school arithmetic word problems. Learning and Instruction, 4,273-294.

Verschaffel, L., De Corte, E. \&Borghart, I. (1997). Pre-service teachers 'conceptions and beliefs about the role of real-world knowledge in mathematical modeling of school word problems. Learning and Instruction, 7(4), 339-359.

Verschaffel, L.,\&DeCorte, E.(1997). Word Problems: A vehicle for promoting authentic mathematical understanding and problem solving in the primary school? In Nunes, $T$ ve Bryant, P. (Eds.). (pp.69-82). Learning and teaching mathematics. An international perspective. UK, Taylor and Francis Group.

Xin, Z., Lin, C., Zhang, L.\&Yan, R. (2007). The performance of Chinese Primary School students on realistic arithmetic word problems. Educational Psychology in Practice, 23 (2), 145-159.

Wyndhamn, J.\&Saljö, R. (1997). Word problems and mathematical reasoning. A study of children's mastery of reference and meaning in textual realities. Learning and Instruction, 7 (4), 361-382.

Yoshida, H., Verschaffel, L. \& De Corte, E. (1997). Realistic considerations in solving problematic word problems: Do Japanese and Belgian children have the same difficulties? Learning and Instruction, 7 (4), 329-338. 